\title{
ESTUDO DO NÚMERO DE ÓBITOS RESPIRATÓRIOS, EXCETO COVID-19, NO RIO GRANDE DO SUL
}

\author{
Pedro_Anjo_Nunes_Neto; ULBRA; pedroanjonunesneto@yahoo.com.br \\ Julia_Bittencourt_Oliveira; UNISINOS; jbttencourt@outlook.com \\ Pablo_Eduardo_Dombrowski; ULBRA; pablodom@rede.ulbra.br \\ Edinês_Carolina_Pedro; UFN; edi_edines@hotmail.com \\ Paulo_Roberto_Cardoso_Consoni ULBRA; paulo.consoni@ulbra.br
}

\section{RESUM0}

Introdução: As doenças respiratórias são responsáveis por grande parte das internações hospitalares de idosos no Rio Grande do Sul, o que desafia programas de atenção e políticas de saúde à pessoa idosa, principalmente pela alta taxa de morbimortalidade na população geriátrica. Idosos com doenças respiratórias apresentam um risco aumentado de óbito neste período de pandemia pelo covid-19, podendo levar à descompensação de doenças respiratórias crônicas. Objetivo: Comparar o número de óbitos de idosos por causas respiratórias, exceto pelo COVID-19, durante a pandemia, no primeiro semestre de 2020, com o mesmo período de anos anteriores. Método: Foi realizado um estudo retrospectivo, quantitativo, que incluiu dados do período entre 2016 e 2020 , excluindo-se os dados do segundo semestre de cada ano. Os dados foram obtidos e analisados a partir do formulário eletrônico do DataSUS. Resultado: Consideraram-se todos os óbitos causados por doenças respiratórias na faixa etária superior a 60 anos, foi constatado um total de 16.393 óbitos no intervalo estudado, com média geral de 3.278,6 mortes a cada primeiro semestre. Destacam-se 2016, com 3.558 óbitos, em contraste com 2020, que registrou 2.984. A pneumonia bacteriana foi responsável por 9.729 registros, representando 59\% das mortes. Conclusão: A redução da mortalidade no primeiro semestre de 2020 por outras doenças respiratórias, provavelmente se deve pelo surgimento de óbitos por casos de COVID-19, mesmo assim, os dados demonstram o alto número de mortes e a gravidade sobre a população idosa portadora de doença do aparelho respiratório.

Palavras-chave: Doenças respiratórias; Geriatria; Óbitos. 